\title{
A review of halotherapy for chronic obstructive pulmonary disease
}

This article was published in the following Dove Press journal:

International Journal of COPD

2I February 20I4

Number of times this article has been viewed

\section{Rachael Rashleigh' \\ Sheree MS Smith ${ }^{1,2}$ \\ Nicola J Roberts ${ }^{3}$}

'Family and Community Health University Research Group, School of Nursing and Midwifery, University of Western Sydney, Campbelltown Campus, Sydney, NSW, Australia; ${ }^{2}$ Centre for Pharmacology and Therapeutics, Division of Experimental Medicine, Imperial College, South Kensington, London, United Kingdom; ${ }^{3}$ Institute of Applied Health Research, School of Health and Life Sciences, Glasgow Caledonian University, Glasgow, Scotland
Correspondence: Rachael Rashleigh Family and Community Health University Research Group, School of Nursing and Midwifery, University of Western Sydney, Locked Bag 1797 Penrith, NSW 275I, Australia

Tel +6I 246203532

Fax +61246203199

Email rachael@rashleigh.com.au
Background: Chronic obstructive pulmonary disease (COPD) is a chronic, progressive disease and is treated with inhaled medication to optimize the patient's lung health through decreasing their symptoms, especially breathlessness. Halotherapy is the inhalation of micronized dry salt within a chamber that mimics a salt cave environment. Recent media reports suggest that this therapy may help with the symptoms of COPD.

Objective: To critically evaluate and summarize the evidence for the use of halotherapy as a treatment for COPD.

Design: A review using systematic approach and narrative synthesis.

Data sources: Cochrane Central Register of Controlled Trials (CENTRAL), PubMed, MEDLINE, EMBASE, CINAHL, and Google Scholar were searched. Two reviewers independently reviewed abstracts and selected eligible studies based on predetermined selection criteria.

Results: Of the 151 articles retrieved from databases and relevant reference lists, only one randomized controlled trial met the inclusion criteria. A meta-analysis was unable to be conducted due to the limited number of published studies. Inclusion criteria were subsequently expanded to allow three case-control studies to be included, ensuring that a narrative synthesis could be completed. From the pooled data of the four studies, there were 1,041 participants (661 in the intervention group and 380 in the control group). The assessment of methodological quality raised issues associated with randomization and patient selection. Three themes were identified from the narrative synthesis: respiratory function, quality of life, and medication use.

Conclusion: Themes generated from the narrative synthesis data reflect outcome measures regularly used for interventional research associated with COPD. From this review, recommendations for inclusion of halotherapy as a therapy for COPD cannot be made at this point and there is a need for high quality studies to determine the effectiveness of this therapy.

Keywords: salt therapy, speleotherapy, lung disease, aerosol, chronic disease, salt cave

\section{Introduction}

Chronic obstructive pulmonary disease (COPD) is a chronic, progressive disease with symptoms of dyspnea, increased respiration rate, sputum production, and a reduced exercise intolerance. ${ }^{1}$ In 2008, the World Health Organization estimated that COPD was the tenth most prevalent cause for moderate to severe disability, ${ }^{2}$ and was the fourth leading cause of death, worldwide. ${ }^{3}$ With this significant burden, the impact of this disease on individuals, families' quality of life, and the associated health care expense, COPD is recognized as an international health priority. ${ }^{1,3,4}$

COPD is managed with inhaled medication with the view to optimize the patient's pulmonary function and reduce symptoms. Pulmonary rehabilitation is recommended for those patients with Medical Research Council dyspnea score of 3 or more $^{1}$ as 
there is substantial evidence of its benefit to these patients. ${ }^{5,6}$ However, other therapies such as speleotherapy and halotherapy are being recommended in the wider community ${ }^{7}$ and are often described as well-researched treatments for people with COPD. ${ }^{8}$ In Eastern Europe, natural salt caves have been used to help relieve symptoms of chest conditions. ${ }^{9}$ This therapy is known as speleotherapy, where a natural salt cave climate is used as a therapy for ill health. ${ }^{10}$ The unique characteristics of the microclimate within the caves are stable air temperature, moderate to high humidity, the presence of fine aerosol elements (sodium, potassium, magnesium and calcium), as well as a lack of airborne pollutants and pollens. ${ }^{11}$ Halotherapy builds on this premise and is used as an above-ground alternative for speleotherapy. ${ }^{12}$ Halotherapy is a treatment consisting of inhalation of small salt particles in a controlled environment of a halochamber. ${ }^{11,12}$ This room is designed to replicate the natural microclimate of a salt cave. Halotherapy treatment has been associated with relief of respiratory conditions such as asthma, cystic fibrosis, and COPD, as well as relieving integumentary conditions such as eczema and dermatitis. ${ }^{9,11}$ A recent study of bronchiectasis patients found halotherapy to be of little benefit. ${ }^{13}$ Despite these findings, there appears to be an increasing number of commercial halotherapy treatment centers in Australia, the United States of America, Europe, and Canada that are aimed at treating respiratory and other medical conditions.

Halotherapy has received prominent television media coverage in Australia from Channel 9's A Current Affair ${ }^{8,14,15}$ and Channel 7's Today Tonight ${ }^{7,16}$ and abroad from Cable Network News' Vital Signs, ${ }^{17}$ as well as from other television program providers such as the British Broadcasting Corporation ${ }^{18}$ and the National Broadcasting Corporation. ${ }^{19}$ National and international media current affair and news reports ${ }^{14-16,19}$ suggest that halotherapy may help with a variety of respiratory illnesses including relieving the symptoms of COPD. The assertion behind these reports is that inhaled dry salt therapy may assist people with COPD by increasing the liquefaction of airway secretions, which, in turn, enhances the expectoration of airway mucous secretions. With the increase in the commercial availability of halotherapy as an alternative complementary treatment, it is timely to undertake a review of this therapy for COPD to appraise the evidence for the complementary therapy. An extensive search of a number of databases did not identify any published systematic reviews that assessed halotherapy as an intervention for people with COPD. Therefore, this review sought to investigate

Table I Summary of included review articles

\begin{tabular}{|c|c|c|c|}
\hline Article & Aim & Sample & Method \\
\hline Nurov $(2010)^{24}$ & $\begin{array}{l}\text { To assess the } \\
\text { immunological features } \\
\text { of COPD patients after } \\
\text { speleotherapy }\end{array}$ & $\begin{array}{l}\text { One hundred twenty-four participants randomized into } \\
\text { two groups. Treatment group } 103 \text { participants ( } 60 \text { male, } \\
43 \text { female) and control group } 25 \text { participants ( } 14 \text { male, } \\
\text { I I female). }\end{array}$ & $\begin{array}{l}\text { Randomized control trial. } \\
\text { Immunological studies at time } \\
\text { one (before treatment), at } \\
\text { time two (after treatment), } \\
\text { and time three ( } 6 \text { months after } \\
\text { treatment). }\end{array}$ \\
\hline $\begin{array}{l}\text { Chervinskaya and } \\
\text { Ziber (1995) }\end{array}$ & $\begin{array}{l}\text { To assess the effect of } \\
\text { halotherapy on various } \\
\text { types of respiratory } \\
\text { diseases }\end{array}$ & $\begin{array}{l}\text { Treatment group - I } 24 \text { participants, } 54 \text { males, } \\
70 \text { females, mean age } 34.3 \pm 2.5 \text { years. Control group - } \\
\text { I } 5 \text { participants not described. }\end{array}$ & $\begin{array}{l}\text { Prospective case-control study. } \\
\text { Lung function studies before and } \\
\text { after trial. }\end{array}$ \\
\hline $\begin{array}{l}\text { Oprita et al } \\
(2010)^{23}\end{array}$ & $\begin{array}{l}\text { To assess the effects of } \\
\text { halotherapy on patients } \\
\text { with asthma and chronic } \\
\text { obstructive pulmonary } \\
\text { disease }\end{array}$ & $\begin{array}{l}\text { Two hundred four participants ( } 61 \% \text { males, mean age } \\
64 \text { years) received standard treatment and SALTMED } \\
\text { treatment. One hundred eighty-nine received only } \\
\text { standard treatment ( } 64 \% \text { males, mean age } 59 \text { years). }\end{array}$ & $\begin{array}{l}\text { Retrospective case-control } \\
\text { study. Respiratory characteristics } \\
\text { reported before treatment and } \\
\text { I hour after treatment. }\end{array}$ \\
\hline Horvath $(1986)^{10}$ & $\begin{array}{l}\text { To examine whether } \\
\text { a stay in a cave } \\
\text { microclimate could } \\
\text { further improve } \\
\text { respiratory symptoms of } \\
\text { patients with COPD or } \\
\text { bronchial asthma }\end{array}$ & $\begin{array}{l}\text { One hundred fifty-one participants - ( } 89 \text { males, } \\
62 \text { females, mean age } 46 \text { years, I0I participants with } \\
\text { chronic bronchitis, } 50 \text { with bronchial asthma) treatment } \\
\text { with climatotherapy. Two hundred thirty participants - } \\
\text { (I } 37 \text { males, } 93 \text { females, mean age } 49 \text { years, } \\
\text { I4I participants had chronic bronchitis, } 89 \text { had } \\
\text { bronchial asthma) treatment was CRR consisting of } \\
\text { speleotherapy in combination with rest, breathing } \\
\text { exercises and relaxation training. }\end{array}$ & $\begin{array}{l}\text { Retrospective case-control } \\
\text { study. Clinical state reported } \\
\text { as improved, unchanged, or } \\
\text { deteriorated. Medication request } \\
\text { dosage changes before and after } \\
3 \text { weeks of treatment. Mean FEV, } \\
\text { before and after treatment. }\end{array}$ \\
\hline
\end{tabular}

Abbreviations: COPD, chronic obstructive pulmonary disease; CRR, complex respiratory rehabilitation; FEV , forced expiratory volume in I second; FVC, forced vital capacity; $\mathrm{PaCO}_{2}$, partial pressure of carbon dioxide in arterial blood; $\mathrm{PaO}_{2}$, partial pressure of oxygen in arterial blood; PEF, peak expiratory flow; SALTMED, saline inhalation; $\mathrm{SaO}_{2}$, oxygen saturation. 
halotherapy as a therapeutic intervention for people with COPD to determine the effectiveness of this therapy.

\section{Methods}

\section{Search strategy and selection criteria}

A search of electronic databases was conducted from January 2013 to February 2013. The electronic databases searched were the Cochrane Central Register of Controlled Trials (CENTRAL), PubMed, MEDLINE, EMBASE, CINAHL, and Google Scholar. The literature review search strategy (Supplementary material) used a combination of MeSH terms found in the title and/or abstract for halotherapy and chronic obstructive pulmonary disease and the following search terms were used: COPD; chronic bronchitis; emphysema; halotherapy; halochamber; speleotherapy; spelaeotherapy; cave; salt mine; potash mine; vital air room; climate chamber; saltpipe; and sopipa. Reference lists in retrieved papers were hand-searched for other possible studies. All prospective randomized controlled trials were included where trials compared halotherapy or speleotherapy with a control group. Abstract and full text articles that were not in English were excluded. After abstracts were retrieved, two reviewers applied the inclusion and exclusion criteria. Full text articles were subsequently obtained and reviewed by two independent reviewers (RR and SMSS) (Table 1). A third reviewer (NJR) was the arbiter should any disagreement regarding the inclusion of articles occur.

\section{Quality assessment}

The methodological quality of the selected articles was assessed by two reviewers (RR and SMSS) using the Scottish Intercollegiate Guidelines Network (SIGN) methodology quality checklists for controlled trials and case-control studies (Table 2). ${ }^{20}$ These checklists were used to assess issues pertinent to well-conducted randomized controlled trials and case-control studies. The risk of bias was assessed using the Cochrane classification with four criteria: sequence generation; allocation concealment; blinding; and incomplete outcome measurement. ${ }^{21}$ Any disagreements regarding risk of bias were resolved through discussions between the reviewers and the arbiter (RR, SMSS, NJR).

\section{Data abstraction}

The search revealed 151 published abstracts after excluding the duplicates. The abstracts were screened using the selection criteria and 150 articles were excluded. The flow diagram of the selection process is illustrated in Figure 1. Only one randomized study met the inclusion criteria; therefore, it

\begin{tabular}{lll}
\hline $\begin{array}{l}\text { NHMRC level } \\
\text { of evidence }\end{array}$ & Major findings & Strengths and limitations \\
\hline II & Increase in concentration subpopulations in all studied & One treatment facility. Moderate sample size. Randomization \\
& lymphocytes, normalization and correlation of & unblinded. Unequal chance of allocation. Recruitment \\
& subpopulations of CD4+ and CD8+ lymphocytes, and increase & strategy not identified. Nil ethical considerations. Patients' \\
& in neutrophil phagocytosis activity. Overall immune status & clinical status not reported.
\end{tabular}

III-2

III-2

III-2 improvement in $97.8 \%$ of treatment group and $67.5 \%$ of control group.

After treatment - decreased bronchial obstruction, decreased medication use, and increase in FVC, FEV , PEF. Participants slept better, decreased fatigue. Cough became less frequent, easier, and more productive.

Respiratory rate, $\mathrm{SaO}_{2}, \mathrm{PaO}_{2}$, and $\mathrm{PaCO}_{2}$ were all significantly improved in the group receiving the standard treatment in combination with the SALTMED treatment as compared to the group receiving only the standard treatment.
One treatment facility. Moderate sample size. Recruitment strategy not identified. Many respiratory diseases grouped together. Nil ethical considerations reported. Control group not adequately described before or after treatment. One treatment facility. Large sample size. Only short term results, no longer term follow up. Asthma and COPD results reported together.

One treatment facility. Large sample size. Asthma and COPD results reported together. Initial clinical state of group receiving $C R R$ was more severe than group receiving climatotherapy. 
was not possible to undertake the meta-analysis. The inclusion criteria were expanded and a further three case-control trials were included. A number of commentary papers were excluded. The two reviewers (RR and SMSS) were in agreement for the studies to be included and the arbiter (NJR) was not required to resolve any conflicting opinion. On completion of the methodological quality assessment, each manuscript was summarized and, due to the heterogeneity of reported outcomes, a thematic analysis was conducted. Thematic analysis is a process that seeks to describe the data in rich detail in order to identify, analyze, and report patterns known as themes from within the data. ${ }^{22}$ The combined data of the four studies were analyzed thematically.

\section{Findings}

\section{Thematic analysis}

Summary data including characteristics of the study regarding the four studies are summarized in Table 1. The three themes identified from the data were respiratory function, quality of life, and medication use.

\section{Respiratory function}

All of the case-control studies $(n=3)$ reported improved respiratory function to varying degrees and detailed improvements in many lung function tests including forced vital capacity, forced expiratory volume in 1 second $\left(\mathrm{FEV}_{1}\right)$, oxygen saturation, partial pressure of oxygen in arterial blood, and partial pressure of carbon dioxide in arterial blood. Although the lung function tests utilized by the researchers are a reliable method to assess respiratory function, each study reported using different tests which made any comparison of the results difficult.

Oprita et $\mathrm{al}^{23}$ report that, after 60 minutes of treatment, there was an improvement in oxygen saturation from $90 \%$ to $98 \%$ in the treatment group $(n=204)$ as compared to the control group $(n=189)$ improving from $94 \%$ to $97 \%$. Similarly, the improvement in partial pressure of oxygen in arterial blood for the treatment group was from $61.5 \mathrm{mmHg}$ to $92 \mathrm{mmHg}$ compared to $80 \mathrm{mmHg}$ to $85 \mathrm{mmHg}$ for the control group. The partial pressure of carbon dioxide in arterial blood considerably decreased in the treatment group from $58 \mathrm{mmHg}$ to $38 \mathrm{mmHg}$ and in the control group from $44 \mathrm{mmHg}$ to $41 \mathrm{mmHg}$.

Horvath $^{10}$ documented an improved respiratory function by measuring the $\mathrm{FEV}_{1}$ before and after treatment. The mean $\mathrm{FEV}_{1}$ for the treatment group $(\mathrm{n}=230)$ improved from $1.47 \pm 0.631 \mathrm{~L}$ to $1.68 \pm 0.71 \mathrm{~L}$ after patients were enrolled in a complex respiratory rehabilitation that included speleotherapy for a specific time period. The control group $(n=151)$, who received climatotherapy, had an improvement from $1.64 \pm 0.61 \mathrm{~L}$ to $1.67 \pm 0.68 \mathrm{~L}$. Nurov's ${ }^{24}$ study reported improved immune function after speleotherapy but did not report specifically on lung function of COPD patients. Nurov concluded that patients with COPD receiving speleotherapy improved their immunological status and, as a consequence, reduced the inflammatory process particularly during exacerbations.

\section{Quality of life}

Horvath $^{10}$ and Chervinskaya and Ziber ${ }^{11}$ reported speleotherapy and halotherapy (respectively) as improving the quality of life for patients suffering from COPD. Horvath reported that $90.4 \%$ of patients receiving the speleotherapy improved their clinical state in comparison to $72.8 \%$ of patients in the control group. The participants' clinical state was scored each day by the participant and physician jointly on the basis of symptoms and complaints. The authors suggested that the improved clinical state for COPD patients improves their life

Table 2 Methodological assessment of included articles

\begin{tabular}{|c|c|c|c|c|c|c|}
\hline & QI & Q2 & Q3 & Q4 & Q5 & Q6 \\
\hline $\begin{array}{l}\text { Randomized } \\
\text { controlled trial }\end{array}$ & Aims & Randomization & Concealment & Double blinding & Similar TG and CG & $\begin{array}{l}\text { Treatment is the only } \\
\text { difference between } \\
\text { TG and CG }\end{array}$ \\
\hline Nurov $(2010)^{24}$ & $\checkmark$ & $\checkmark$ & Unable to report & $x$ & $\checkmark$ & $\checkmark$ \\
\hline $\begin{array}{l}\text { Case-control } \\
\text { studies }\end{array}$ & Aims & $\begin{array}{l}\text { Comparable } \\
\text { populations }\end{array}$ & $\begin{array}{l}\text { Consistent } \\
\text { exclusion criteria }\end{array}$ & $\begin{array}{l}\text { Percentage of cases } \\
\text { and controls }\end{array}$ & $\begin{array}{l}\text { Comparison of cases } \\
\text { and controls }\end{array}$ & Clearly defined cases \\
\hline $\begin{array}{l}\text { Chervinskaya and } \\
\text { Ziber (1995) }{ }^{\prime \prime}\end{array}$ & $\checkmark$ & $\begin{array}{l}\text { Unable to } \\
\text { report }\end{array}$ & Unable to report & Unable to report & $x$ & $x$ \\
\hline $\begin{array}{l}\text { Oprita et al } \\
(2010)^{23}\end{array}$ & $\checkmark$ & $\checkmark$ & $\checkmark$ & Unable to report & $\checkmark$ & $\checkmark$ \\
\hline Horvath $(1986)^{10}$ & $\checkmark$ & $\checkmark$ & Unable to report & Unable to report & $\checkmark$ & $\checkmark$ \\
\hline
\end{tabular}

Note: Overall acceptability is indicated by $(-)$ unacceptable, $(+)$ acceptable, and $(++)$ excellent.

Abbreviations: Q, question number; CG, control group; TG, treatment group. 
quality by decreasing exacerbations, reducing hospitalization, improving physical tolerance, and reducing fatigue. Nurov ${ }^{24}$ reported that positive shifts in immunological status resulted in improved clinical symptoms, but elaboration or description of clinical symptoms were not provided.

\section{Medication use}

The use of medication was an outcome measured in two halotherapy studies. Chervinskaya and Ziber ${ }^{11}$ and Horvath ${ }^{10}$ indicated that patients were able to decrease their medications. Chervinskaya and Ziber reported that up to $50 \%$ of patients in their study were able to discontinue their inhaled corticosteroids therapy and nearly a third of participants continued their inhaled steroid therapy at reduced dosages. In Horvath's study, medication use was recorded as a bi-level outcome with the first outcome being reduction or omission and the second outcome being an unchanged dosage. However, with $95 \%$ of participants having either reduced or omitted medication, the type of medication or dosage is not detailed.

\section{Discussion}

From this review of literature, it has become apparent that there have been very few rigorous studies published on this topic and, hence, this reduces the potential for evidence to support this therapy. It should be noted that only one randomized trial was found after an extensive search of the literature. As a result, the inclusion criteria for this review were widened to include relevant case-control studies that met all other inclusion criteria. The randomized trial by Nurov $^{24}$ studied the immunological features of patients with COPD before and after speleotherapy, demonstrating increased levels of lymphocytes and increased neutrophil phagocytosis activity. When assessing the methodological quality of studies included in this review, a number of concerns were identified.
Specifically, in Nurov's study, the method of randomization appeared unclear and there was a lack of detail regarding demographic and disease related information including medications being used by participants.

Other concerns related to the studies included in this review pertain to the lack of detail in regard to the participants' primary medical condition of either asthma or COPD and discrimination in the results between these two medical conditions. Medication information including type and dosage was also lacking in all studies. There were significant differences at baseline between treatment and control arms in the study by Oprita et $\mathrm{al}^{23}$ and the treatment group appeared to have more severe COPD. In Horvath's ${ }^{5}$ study, the patients in the treatment group had a significantly lower $\mathrm{FEV}_{1}$ prior to the intervention than the control group. Whilst the Oprita study appears to be a well-constructed retrospective case-control study with positive results for the use of sodium chloride dry aerosols, as the investigators only assessed patients 1 hour after treatment, longer term conclusions such as quality of life would be difficult to assess.

In light of the lack of scientific evidence for the use of halotherapy in COPD, future studies need to be designed to provide the best available evidence and randomized controlled trials need to be considered. This approach would address the methodological concerns identified through this review such as participant selection bias, blinding of participants to the intervention, and the concealment of allocation to intervention or control group.

\section{Study limitations}

The limitations associated with this review were restricted by the availability of published research associated with halotherapy as a therapeutic intervention for COPD. The studies included in this review were found to have a

\begin{tabular}{|c|c|c|c|c|c|}
\hline Q7 & Q8 & Q9 & Q10 & QII & \\
\hline $\begin{array}{l}\text { Outcome measured } \\
\text { in standard, valid, } \\
\text { reliable way }\end{array}$ & $\begin{array}{l}\text { Drop out } \\
\text { percentage }\end{array}$ & $\begin{array}{l}\text { Intention to treat } \\
\text { analysis }\end{array}$ & $\begin{array}{l}\text { Results comparable } \\
\text { for all sites }\end{array}$ & - & $\begin{array}{l}\text { Overall acceptability } \\
(++,+,-)\end{array}$ \\
\hline$\checkmark$ & Not reported & $\checkmark$ & $\mathrm{N} / \mathrm{A}$ & & + \\
\hline $\begin{array}{l}\text { Clearly defined } \\
\text { controls }\end{array}$ & Concealment & $\begin{array}{l}\text { Outcome measured in } \\
\text { standard, valid, reliable way }\end{array}$ & $\begin{array}{l}\text { Address possibility of } \\
\text { confounding factors }\end{array}$ & $\begin{array}{l}\text { Confidence intervals } \\
\text { provided }\end{array}$ & $\begin{array}{l}\text { Overall acceptability } \\
(++,+,-)\end{array}$ \\
\hline$x$ & Unable to report & $x$ & $x$ & $x$ & 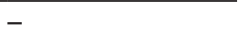 \\
\hline$\checkmark$ & $\begin{array}{l}\text { Retrospective } \\
\text { case-control study }\end{array}$ & $\checkmark$ & $\checkmark$ & $\checkmark$ & ++ \\
\hline$\checkmark$ & $\begin{array}{l}\text { Retrospective } \\
\text { case-control study }\end{array}$ & $\checkmark$ & $\checkmark$ & $x$ & + \\
\hline
\end{tabular}




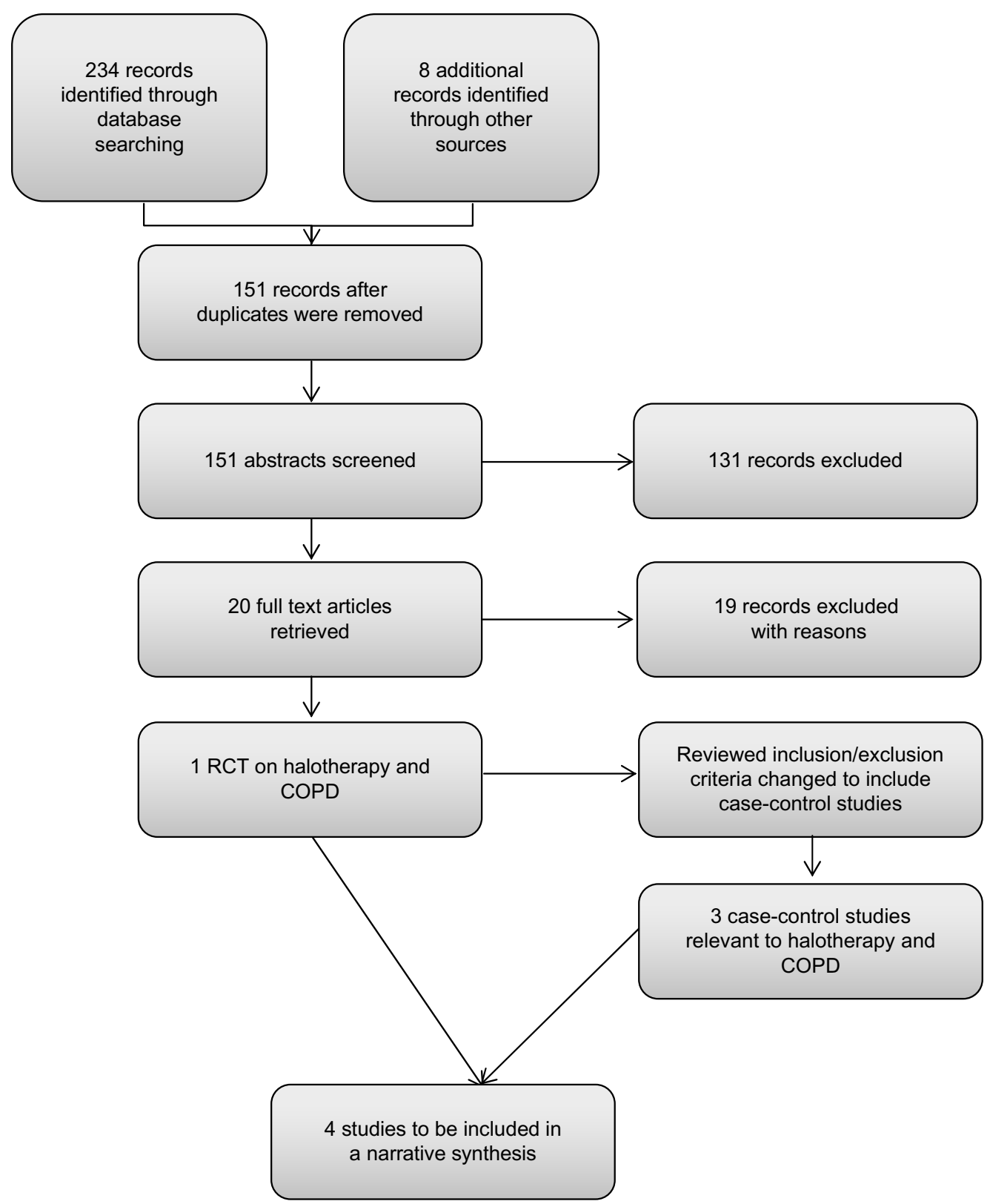

Figure I Flow chart of systematic search.

Abbreviations: COPD, chronic obstructive pulmonary disease; RCT, randomized controlled trial.

number of methodological concerns and limited reporting of baseline data. All studies in this review lacked detail on ethical considerations such as ethical approval, processes for informed patient consent, and funding disclosure. The outcome measurements using lung function tests varied between studies and, as such, a comparison of their results was not possible.

\section{Conclusion}

For halotherapy to be considered as an evidence based therapy for people with COPD, there needs to be high quality research undertaken to fully examine the effects of this therapy and its impact on the quality of life of people with COPD.

\section{Disclosure}

The authors report no conflicts of interest in this work.

\section{References}

1. National Institute for Health and Care Excellence. CG101: Chronic Obstructive Pulmonary Disease (updated) [webpage on the Internet]. 2010. Available from: http://guidance.nice.org.uk/CG101. Accessed January 14, 2014.

2. World Health Organization. The Global Burden of Disease 2004 Update. 2008. Accessed January 10, 2014. 
3. Raherison C, Girodet PO. Epidemiology of COPD. Eur Respir Rev. 2009;18:213-221.

4. Donaldson GC, Wedzicha JA. COPD exacerbations 1: Epidemiology. Thorax. 2006;61:164-168.

5. Global Strategy for Diagnosis, Management, and Prevention of COPD [webpage on the Internet]. Global Initiative for Chronic Obstructive Lung Disease; 2013. Available from: http://www.goldcopd.org/ guidelines-global-strategy-for-diagnosis-management.html.

6. Abramson MJ, Crockett AJ, Frith PA, McDonald CF. COPDX: an update of guidelines for the management of chronic obstructive pulmonary disease with a review of recent evidence. Med J Aust. 2006;184:342-345.

7. Brady C. Ancient treatment revamped [webpage on the internet]. Yahoo!7 News; 2012. Available from: http://au.news.yahoo.com/ today-tonight/latest/article/-/12487174/ancient-treatment-revamped/. Accessed January 17, 2013.

8. Grimshaw T. Salt therapy [webpage on the Internet]. Ninemsn; 2012. Available from: http://aca.ninemsn.com.au/article/8472866/ salt-therapy. Accessed January 17, 2013.

9. Horowitz S. Salt Cave Therapy: Rediscovering the Benefits of an Old Preservative. Alternative and Complementary Therapies. 2010;16:158-162.

10. Horvath T. Speleotherapy: a special kind of climatotherapy, its role in respiratory rehabilitation. Int Rehabil Med. 1986;8:90-92.

11. Chervinskaya AV, Ziber NA. Halotherapy for treatment of respiratory diseases. J Aerosol Med. 1995;8:221-232.

12. Chervinskaya AV. Halotherapy of respiratory diseases. Physiotherapy, Balneology and Rehabilitation. 2003;6:8-15.

13. Rabbini B, Makki SSM, Najafizadeh K. Efficacy of Halotherapy for Improvement for Pulmonary Function Tests and Quality of Life of NonCystic Fibrosis Bronchiectatic Patients. Tanaffos. 2013;12:22-27.

14. Alpins M. A salty solution [webpage on the internet]. Ninemsn; 2011. Available from: http://aca.ninemsn.com.au/article.aspx?id=8222811 Accessed April 30, 2013.
15. Rossi M. Salt therapy [webpage on the Internet]. Ninemsn; 2011 Available from: http://aca.ninemsn.com.au/article.. spx $? \mathrm{id}=8280493$. Accessed April 30, 2013.

16. Richardson D. Salt Rooms [webpage on the Internet]. Yahoo!7 News; 2010. Available from: http://au.news.yahoo.com/today-tonight/health/ article/-/7892980/salt-rooms/. Accessed April 30, 2013.

17. Gupta S. Salt cave offers saline solution to sinus problems [webpage on the Internet]. Atlanta: Cable News Network, Inc.; 2009. Available from: http://edition.cnn.com/2009/HEALTH/06/23/salt.cave.uk/. Accessed April 30, 2013.

18. British Broadcasting Corporation. Salt Cave opens in Kent to aid respiratory problems [webpage on the Internet]. Available from: http:// news.bbc.co.uk/local/kent/hi/front_page/newsid_9191000/9191803. stm. Accessed April 30, 2103.

19. Kim J. Salt therapy makes a comeback [webpage on the Internet]. New York: NBC News; 2011. Available from: http://www.nbcnews. com/video/nbc-news/42748116\#42748116. Accessed April 30, 2013.

20. Methodology Checklists [webpage on the Internet]. Scottish Intercollegiate Guidelines Network; 2013. Available from: http://www.sign. ac.uk/methodology/checklists.html. Accessed January 18, 2013.

21. Risk of Bias. In: Higgins JPT, Green S, editors. Cochrane Handbook for Systematic Reviews of Interventions, Version 5.1.0 [updated March 2011]. The Cochrane Collaboration.

22. Braun V, Clarke V. Using thematic analysis in psychology. Qual Res Psychol. 2006;3:77-101.

23. Oprita B, Pandream C, Dinu B, Aignătoaie B. Saltmed - The therapy with sodium chloride dry aerosols. Therapeutics, Pharmacology, and Clinical Toxicology. 2010;XIV:201-204.

24. Nurov I. Immunologic features of speleotherapy in patients with chronic obstructive pulmonary disease. Medical and Health Science Journal. 2010;2:44-47. 


\section{Supplementary material \\ Search strategy}

A systematic search of the bibliographic databases was conducted using the following search terms: COPD or "Chronic bronchitis" or Emphysema and Halotherapy* or halochamber* or spelaeo* or speleo* or cave* or salin* or "salt min*" or "potash min*" or subterraneotherap* or "vital air room" or "climat* chamber" or karst* or SaltPipe or Sopipa.

\section{Publish your work in this journal}

The International Journal of COPD is an international, peer-reviewed journal of therapeutics and pharmacology focusing on concise rapid reporting of clinical studies and reviews in COPD. Special focus is given to the pathophysiological processes underlying the disease, intervention programs, patient focused education, and self management protocols.
This journal is indexed on PubMed Central, MedLine and CAS. The manuscript management system is completely online and includes a very quick and fair peer-review system, which is all easy to use. Visit http://www.dovepress.com/testimonials.php to read real quotes from published authors. 